\title{
Design and Implementation of an Intelligent Security System for Farm Protection from Wild Animals
}

\author{
Prof. Abhinav V. Deshpande \\ Assistant Professor, Department of Electronics \& Telecommunication Engineering Prof. Ram Meghe Institute of Technology \& \\ Research Badnera, Amravati-444701 \\ avd.a.deshpande@gmail.com
}

\begin{abstract}
Crops are vulnerable to wild animals. Therefore, it is very important to monitor the nearby presence of animals. Then the actuation of various devices should follow to repel the hazardous animals. Traditional methods have been widely applied depending on the kinds of produce and imperilling animals. In this paper, we propose a method to protect farms from wild animals via ubiquitous wired network devices, which is applied to farm along with traditional methods to improve the protection performance. Operational amplifier circuits are utilized mainly for the detection of animal intrusion from the outside of farms. The proposed monitoring scheme is to provide an early warning about possible intrusion and damage by wild animals.
\end{abstract}

Keywords: Microcontroller, ADC, LDR, GSM

\section{Introduction}

In the world, the economy of many countries is dependent upon agriculture. In spite of economic development agriculture is the backbone of the economy. Agriculture is the main stay of economy. It contributes to the gross domestic product. Agriculture meets food requirements of the people and produces several raw materials for industries. But because of animal interference in agricultural lands, there will be huge loss of crops. Crop will be totally getting destroyed. There will be large amount of loss of farmer. To avoid these financial losses it is very important to protect agricultural field or farms from animal. To overcome this problem, in our proposed work we shall design a system to prevent the entry of animals into the farm. Our main purpose of project is to develop prohibitive fencing to the farm, to avoid losses due to animals. These prohibitive fencing protect the crop from damaging that indirectly increase yield of the crop. The develop system will not harmful and injurious to animal as well as human beings. Theme of project is to design a intelligent security system for farm protection by using Embedded system [1][2].

\subsection{Scope of Work}

1. To design a security system for farm protection

2. Prohibit the entry of animal into the farm

3. Use GSM module for alerting us

4. Design a system that sounds when animal tries to enter into the farm

5. In night flash light will focus on that side.

\section{Literature Survey}

An electric fence was used as a barrier to protect a farm from wild animals. An electric fence was first used in Texas in 1888. Electricity from a generator using an overshot wheel was to charge the top two wires of a four- wire fence [1]. Often solar-powered, such fences were used extensively in the Panhandle to prevent cattle from wandering onto farmlands [2]. One major disadvantage of an electric fence is that it might slow down emergency services from reaching you. This might even result in help reaching you after it is too late. There is a possibility of electric fences posing the risk of fire when bushes or trees grow in close proximity. Hence, it is important to keep the area near the fence cleared of any such vegetation. It will also have to ensure that the grounding has been done properly. Failure to do so might render the electric fence ineffective. In this case there will be loss of animal life and it is very dangerous to human being also. It will be too much expensive for farmers [1][3].

\subsection{Proposed Work}

In our proposed work, fencing wire is used as a sensor. When animals come in contact with this open cable the circuit will be grounded and we get initial input signal that indicates presence of animals at fencing. After getting that initial input signal followed by amplifier circuit passed it for further processing. Then it will be given to the microcontroller. Our system will be activated, immediately buzzer will be on, at the time of night flash light will be on and message will be sent to the farmer. Power supply will be given by solar panel or from regulated power supply [2][4]. In this project fencing wire act as a Sensor but resistance of this wire is large so we need to use Amplifier circuit ,so that small change in fencing wire will be amplified and giving it to the ADC of microcontroller, so that our system will be activated. Microcontroller Block is used for reading the resistance of fencing and also reading the LDR and operates when thresholds gets cut off, also it operates Buzzer or Focus Light according to Light Intensity. Whole process is controlled by microcontroller. The GSM module is used for sending SMS to farmer when threshold gets cut off. It alerts the farmer that some animals try to enter into the farm. Shifter circuit is used 


\section{International Journal of Science and Research (IJSR) \\ ISSN (Online): 2319-7064 \\ Index Copernicus Value (2013): 6.14 | Impact Factor (2014): 5.611}

for isolation between GSM module and microcontroller. LCD use to Display values of ADC of microcontroller, from where we know we get the initial input to our system. Our LCD data will be display for SMS sending .There will be keypad for changing the setting of system. Relay and its driver are used for torch controlling [1][5].

\section{System Architecture and Description}

\subsection{Block Diagram of the Proposed System}

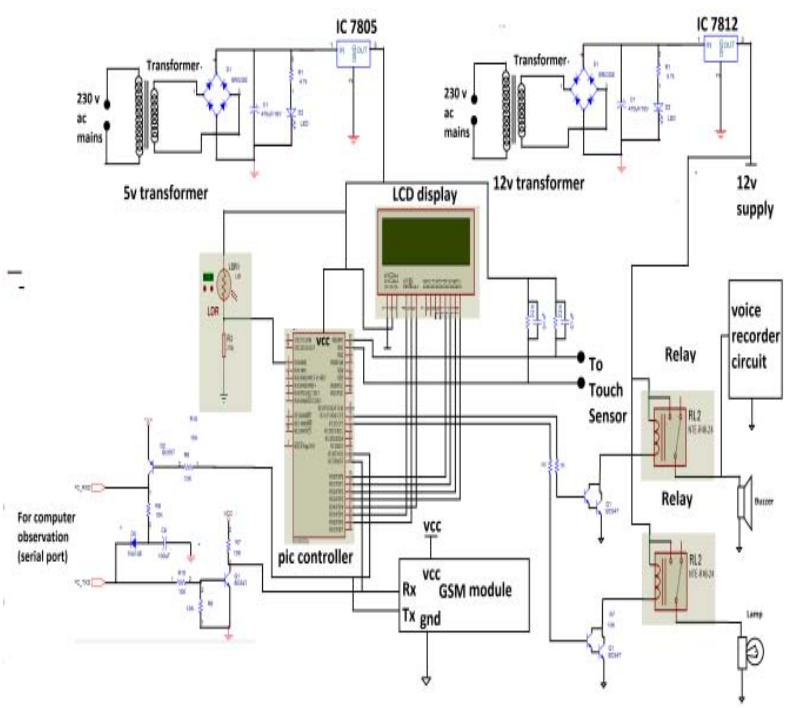

Figure 1: Block Diagram of the Proposed System

\subsection{Description of Blocks of the Proposed System}

\subsubsection{Microcontroller Pic16f877a}

1. High-Performance RISC CPU:

2. Only 35 single-word instructions to learn

3. All single-cycle instructions except for program branches, which are two-cycle

4. Operating speed: DC $-20 \mathrm{MHz}$ clock input DC -200 ns instruction cycle

5. Up to $8 \mathrm{~K}$ x 14 words of Flash Program Memory,

6. Up to $368 \times 8$ bytes of Data Memory (RAM),

7. Up to $256 \times 8$ bytes of EEPROM Data Memory

8. Pin out compatible to other 28-pin or 40/44-pin

\subsubsection{Peripheral Features}

1. Timer0: 8-bit timer/counter with 8-bit prescalar

2. Timer1: 16-bit timer/counter with prescalar, can be incremented during Sleep via external crystal/clock

3. Timer2: 8-bit timer/counter with 8-bit period register, prescalar and postscalar

4. Two Capture, Compare, PWM modules

5. Capture is 16-bit, max. Resolution is $12.5 \mathrm{~ns}$

6. Compare is 16-bit, max. Resolution is $200 \mathrm{~ns}$

7. PWM max. Resolution is 10-bit

8. Synchronous Serial Port (SSP) with SPITM (Master mode) and I2C TM (Master/Slave)

9. Universal Synchronous Asynchronous Receiver Transmitter (USART/SCI) with 9-bit address detection

10. Parallel Slave Port (PSP) -8 bits wide with external
RD, WR and CS controls (40/44-pin only) 11. Brown-out detection circuitry for Brown-out Reset (BOR)

\subsubsection{Analog Features}

1.10-bit, up to 8-channel Analog-to-Digital Converter (A/D)

2. Brown-out Reset (BOR)

3. Analog Comparator module with:

4. Two analog comparators

5. Programmable on-chip voltage reference (VREF) module

6. Programmable input multiplexing from device inputs and internal voltage reference

7. Comparator outputs are externally accessible.

\subsubsection{Device Overview}

This document contains device specific information about the following devices:

1. PIC16F873A

2. PIC16F874A

3. $\mathrm{PIC} 16 \mathrm{~F} 876 \mathrm{~A}$

4. PIC16F877A

PIC16F873A/876A devices are available only in 28-pin packages, while PIC16F874A/877A devices are available in 40-pin and 44-pin packages. All devices in the PIC16F87XA family share common architecture with the following differences:

1. The PIC16F873A and PIC16F874A have one-half of the total on-chip memory of the PIC16F876A and PIC16F877A.

2. The 28-pin devices have three I/O ports, while the 40/44-pin devices have five.

3. The 28-pin devices have fourteen interrupts, while the 40/44-pin devices have fifteen.

4. The 28-pin devices have five A/D input channels, while the 40/44-pin devices have eight.

5. The Parallel Slave Port is implemented only on the 40/44-pin devices.

\subsubsection{Memory Organization}

There are three memory blocks in each of the PIC16F87XA devices. The program memory and data memory have separate buses so that concurrent access can occur and is detailed in this section [2].

\section{Research Methodology to Be Employed}

To implement this project we have used PIC controller for Much Flash memory for project operation. The RISC (Reduced Instructions Set Computer) microcontroller is a powerful tool that provides a highly flexible and costeffective solutions to many embedded monitoring and diagnostic systems [1][3]. The central unit has been made around of a PIC microcontroller with proposed architecture which will be used for Farm protector system, also Easy to program it and writing or burning 


\section{International Journal of Science and Research (IJSR) \\ ISSN (Online): 2319-7064 \\ Index Copernicus Value (2013): 6.14 | Impact Factor (2014): 5.611}

devices are available it also have inbuilt timers and presale mode to operate timers for Farm protector, Four relay is used for MOTOR driving, all these motors are in forward direction so we used relay it is directly connected to controller and internal timer used object sorting timers and we used LCD $16 * 2$ for which object is detected and. Regulated power supply is used and step down transformer for this output of power supply is 5 Volt and 12 Volt unregulated. For Display we used a LCD of $16 \times 2$ types. The most common connector used for the LCDs is 14 pins in a row.

\section{Applications, Features and the Advantages and Disadvantages of Our Proposed System}

\section{1. Advantages}

1. LDR reading are automatic and displayed on a 2 digit and LCD display.

2. Continuous monitoring can be done.

3. Works on Solar panel, AC mains or batteries.

4. Fine design.

5. Mini appearance.

\section{2. Disadvantages}

1. In large scale devise handling will be complex.

2. Mechanical assembly is more complex.

3 . Battery always checks for charging.

\section{3. Features}

o Simple circuit and easy to operate.

o Fast and simple installation.

o Location flexibility.

o Low cost maintenance.

o Automatic operation.

- High reliability and long lifetime.

$\circ$ Digital display

\section{4. Applications}

1. Main application it is used to protect farm.

2. To be used in orchard/fruit garden.

3 . To be used for vegetable garden.

4. To be used for security system for houses.

\section{Conclusion and Future Scope}

In this way by connecting an amplifier circuit on fencing, if fencing circuit is grounded by touching it to the animal then our system will be activated. Buzzer will be activated and by using LDR it detects light intensity, if it is less, it will focus the light. So that wild animals will not enter into the farm. It will run away. GSM module sends message to the farmer to alert him, after the activation of system. From this it is concluded that the design system is very useful and affordable to the farmer. The design system will not be dangerous to animal and human being, and it protects farm. In the future, there will be very large scope, this project can be made based on Image processing in which wild animal can detect by cameras and if it comes towards farm then system will be directly activated through wireless networks. Wild animals can also be detected by using wireless networks such as laser wireless sensors and by sensing this laser or sensor's security system will be activated.

\section{Acknowledgements}

This research work was undertaken as a part of technical education quality improvement program (TEQIP-2) which was sponsored by MHRD, India in order to improve the current quality of technical education which is imparted to the students in different parts of the country. I would like to thank the Head of Department, Department of Electronics \& Telecommunication Engineering, Prof. Ram Meghe Institute of Technology \& Research, Badnera, Amravati-444701.

\section{References}

[1] Dr. Wilson, "ELECTRIC FENCE," Handbook of Texas, Project report published by the Texas State Historical Association. August 4, 2011

[2] T. Day and R. Mac Gibbon, "Multiple-Species Exclusion Fencing and Technology for Mainland Sites.”, Project Report published by National Wildlife Research Centre, 2007.

[3] R. Padula and W. Head, "Fencing System" Project Report published by University of Minnesota, 2003.

[4] A. Stoler, "Taut Wire Fence System," U.S. Patent 4,730,809, March 1988.

[5] N. V. Bekarts, "Security fence," A - European Patent EP0014009, December 1982

\section{Author Profile}

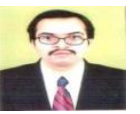

My name is Prof. Abhinav V. Deshpande. I have done S.S.C. in the branch of Science from Somalwar Nikalas High School, Nagpur in the year 2000 with an aggregate of $73 \%$. I have done H.S.S.C. in the branch of Electronics from Jupiter Science Junior College, Nagpur in the year 2002 with an aggregate of $54 \%$. I have done B.E. in the branch of Electronics \& Telecommunication Engineering from G.H. Raisoni College of Engineering, Nagpur in the year 2010 with an aggregate of $63 \%$. I have done M.Tech. in the branch of Electronics Engineering from the same institute in the year 2012 with a CGPA of 7.90 on a scale of 10.00. I have passed the Ph.D. Entrance Test (PET) which was conducted by RTM Nagpur University in the year 2013 with a valid score of 55 marks out of 100 and in the year 2015 with a valid score of 55.75 marks out of 100. I have also passed the Ph.D. Entrance Test (PET) of Gondwana University in the year 2015 with a valid score of 51 marks out of 100. My areas of research include Digital Signal Processing, Digital Image Processing, VLSI, Soft Computing and Applications, Embedded Systems, Intelligent Transportation Systems etc. I have published 19 research papers in different and reputed International Journals and 1 research paper in International Conference. I have also published 1 book in 


\section{International Journal of Science and Research (IJSR) \\ ISSN (Online): 2319-7064}

Index Copernicus Value (2013): 6.14 | Impact Factor (2014): 5.611

Saarbrucken, Germany. I am having the memberships of different professional organizations like ISTE, IE (I), IEEE, IETE, UACEE, IET etc. I want to do Ph.D. in the branch of Electronics Engineering and also I want to do D.Sc. in the branch of Electronics Engineering as a future career option. I am working as an Assistant Professor on Contract Basis in the Department of Electronics \& Telecommunication Engineering at Prof. Ram Meghe Institute of Technology \& Research, Badnera, Amravati-444701 at present and I want to do a career in the field of Research \& Development in the domain of Electronics Engineering. 